\title{
Effects of feeding genetically modified (GM) maize on oxidative stress parameters in New Zealand rabbit
}

\author{
Yalçin E. ${ }^{1}$, Acar A. ${ }^{2,}{ }^{*}$, Seven B. ${ }^{1}$, Taşli B. ${ }^{1}$ and Çavuşoğlu K. ${ }^{1}$ \\ ${ }^{1}$ Giresun University, Science and Art Faculty, Biology Department, Giresun, Turkey \\ ${ }^{2}$ Giresun University, Vocational School of Health Services, Department of Medical Services and Techniques, Giresun, Turkey \\ Received: 25/05/2017, Accepted: 28/08/2017, Available online: 30/01/2018 \\ *to whom all correspondence should be addressed: e-mail: ali.acar@giresun.edu.tr
}

\begin{abstract}
In this study, we investigated the effects of Genetically Modified (GM) Maize on liver and kidney organ weights, malondialdehyde (MDA) and glutathione (GSH) levels of liver and kidney tissues in New Zealand Rabbits. For this purpose, rabbits were divided into three groups: parental, first-generation and second-generation. Each group was divided into two sub-groups i.e. control group and the treatment group. Rabbits on the control group were fed with conventional maize (non-GM), whereas rabbits which are in the treatment groups were fed with GM maize. Six females and six male New Zealand rabbits were used per group. At the end of the experimental period, tissue samples were taken and organ weights, MDA and GSH levels were determined. Overall, as the generations progressed, a statistically significant increase in liver weights and a decrease in kidney weights were observed. There was no statistically significant change as regards MDA and GSH levels of liver and kidney tissues of groups without GM maize inclusion in the diet. However, in all three-generation of GM maize treated groups, there was a significant decrease in GSH levels and a significant increase in MDA levels were observed.
\end{abstract}

Keywords: Genetically modified organism, malondialdehyde, glutathione, feeding, rabbit.

\section{Introduction}

Genetic modification is a method that allowing introduction of new genes and components to organisms. However, these new genes can cause stress in living organisms and can also cause undesirable metabolic changes. These changes can also result to alterations in the amount of antioxidant ingredients and nutrient-critical components. Despite adverse effects; because of its advantages, cereals produced by utilizing these modern techniques have widely been used throughout the world. By its rich nutritional content and high efficiency, the maize plant has an important place among the most cultivated genetically modified crops in the world. Although genetic modifications in maize plants are carried out, in general, to increase crop yield, however the transfer of insect resistance genes to maize lines both increases corn yield and significantly reduces insecticide use (El-Sanhoty et al., 2006; Dickerson, 2008; Halford, 2012).

The most commonly investigated and used GM maize is the hybrid known as maize "Bt maize" containing the Bacillus thuringiensis bacteri gene. Bacillus thuringiensis bacteria form crystals in the protein structure during the sporulation of the body. These crystals exhibit lethal activity against virus and insects. The crystals settle in the middle intestinal epithelial cells of insects and cause intestinal spasm. These crystals bind to the receptors on the surface of epithelial cells, blocking the cellular pores and causing cell disfunction. Hosts' cells or larvae die as a result of this effect, and the maize plant becomes resistant to insects (Brake and Vlachos, 1998).

Many studies have reported negative effects on living organisms after feeding with genetically modified products. Liver atrophy in GM potato-fed rats, liver lesions in GM maize-fed rats and liver enzyme alterations in GM soybeen-fed rabbits are some of the findings in literature (Burns, 2002; Tudisco,2006; Kizil and Çay, 2010).

In a study conducted by Seralini et al., (2012) increase in gamma glutamyl transferase activity in the liver of mice fed with genetically modified maize was reported. However, mRNA and rRNA transcription has also been reported to be decreased due to the formation of intense heterochromatin. In the same study, liver and kidney tissues of mice fed GM crops were examined pathologically and macroscopic/microscopic necrotic areas were reported to be 2.5 times more than the control group (Seralini et al., 2012).

This study aims at investigating the oxidative stress parameters of the liver and kidney tissues in New Zealand Rabbits fed GM maize during two generation. Oxidative stress can cause many disorders such as heart diseases, cancer, cardiovascular disease. For this reason, it is very important to determine the oxidative stress in tissues. MDA is the lipid peroxidation product that results from the oxidative damage, and is an important indicator of oxidative stress. Antioxidant molecules such as GSH, protect cells against oxidant molecules in living organisms (Santos et al.,1980; Pompella et al., 2003). 
For this purpose, GSH and MDA levels of liver and kidney tissues were measured to evaluate oxidative stress, so that, the effect of GM maize on stress indicators in rabbits is clarified.

\section{Materials and Methods}

This study was conducted with 12 New Zealand rabbits (Oryctolagus cuniculus). Parental rabbits were divided into two groups; control group (Group I: 3 female, 3 male) and GM maize treated group (Group II: 3 female, 3 male).First generation rabbits which came from parentals were separated as control group (Group III: 3 female, 3 male) and GM maize treated group (Group IV: 3 female, 3 male). Similiarly, second generation rabbits which came from first generation were separated as control group (Group V: 3 female, 3 male) and GM maize treated group (Group VI: 3 female, 3 male).

The rabbits were maintained under controlled conditions at $22 \pm 3^{\circ} \mathrm{C}, 50 \pm 5 \%$ relative humidity and 12 -h dark/light cycles during experimental period. The methods used in this study were carried out in accordance with the guidelines set by the World Health Organization (Geneva, Switzerland) and guidelines of Animal Experiments Local Ethical committee-Giresun University. Control group rabbits were fed with $150 \mathrm{~g}$ of maize and tap water per day and rabbits in the treatment group were fed with $150 \mathrm{~g}$ of GM maize and tap water.The study was terminated when second-generation mice reached sexual maturity and were not allowed to reproduce. At the end of the experimental period, rabbits were slaughtered under ether anesthesia and tissue samples were taken.

\subsection{Measurement of Organ Weights and Oxidative parameters}

At the end of experimental period, kidney and liver tissues of the rabbits were removed, tissue weight determination and oxidative analyzes were performed. Liver and kidney tissue weights were detected with precision scales.

\subsection{MDA Analysis}

Oxidative stress in liver and kidney tissues were investigated by measuring thiobarbituric acid reactive substance formation, a marker of malondialdehyde production. Liver and kidney tissues were homogenized in $0.15 \mathrm{M} \mathrm{KCl}$ (cold) by a homogenizator. After centrifugation at $16000 \mathrm{rpm}$ for $3 \mathrm{~min}$, MDA concentration was determined. For this aim, $1.0 \mathrm{~mL}$ of trichloroacetic acid (20\%) and $1.0 \mathrm{~mL}$ of thiobarbituric acid reactive substance (1\%) were mixed to $100 \mu \mathrm{L}$ of supernatant, and incubated at $100{ }^{\circ} \mathrm{C}$ for $80 \mathrm{~min}$. After cooling procedure, samples were centrifuged for $15 \mathrm{~min}$ and the absorbance was recorded spectrophotometrically at $532 \mathrm{~nm}$. MDA level was expressed as nmole $\mathrm{g}^{-1}$ (Yoshioka et al., 1979).

\subsection{GSH Analysis}

GSH is the body's main internal antioxidant and is decresed in cases of oxidative stres, so the determination of GSH level is very important for the evaluation of oxidative stress. Liver and kidney tissues were homogenized in 0.15 $\mathrm{M} \mathrm{KCl}$ (cold) by a homogenizator. After centrifugation at
$16000 \mathrm{rpm}$ for $3 \mathrm{~min}$, GSH concentration was measured. For GSH analysis, $2 \mathrm{~mL} \mathrm{5,5}$ dithio-bis-2-nitrobenzoic acid (0.6 mM) was mixed with $0.1 \mathrm{~mL}$ of the supernatant and the absorbance was recorded spectrophotometrically at $412 \mathrm{~nm}$. GSH level was expressed as $\mathrm{mg} \mathrm{g}^{-1}$ (Beutler et al., 1963).

\section{Results and discussion}

The changes in liver and kidney tissue weights induced by GM maize application are given in Figure 1. It was observed that the weights of liver tissues in Group I, Group III and Group V (without GM maize application) did not change. But in Group II, IV and VI, as the generations progressed, a statistically significant increase in liver organ weights was observed $(p<0.05)$. In kidneys, as the generations progressed, it was found that there was a statistically significant decrease $(p<0.05)$ in kidney organ weights of Group II, IV and VI. In addition, it was observed that the weights of kidney tissues in Group I, III and V (without GM maize application) did not change.

The effects of GM maize application on the oxidative stress parameter as MDA levels are given in Table 1. There was no statistically significant change in liver and kidney MDA levels in Group I, III and V (without GM maize application) $(p>0.05)$. In all three-generation of GM maize treated groups, it was determined that MDA levels were increased and this increase was statistically significant.In general, it was observed that MDA levels were higher for kidney tissues in all generations. The highest MDA level was detected in kidney tissues of GM maize treated second generation rabbits as $0.84 \mathrm{nmole}^{-1}$. In second generation of GM maize treated rabbits, kidney and liver MDA levels were 1.71 and 2.17 times higher than the parental counterpart, respectively. However, changes in MDA levels for all generation were more prominent in the liver compared to kidney tissues.

The effects of GM maize application on the GSH levels are given in Table 2. There was no statistically significant change in GSH levels of liver and kidney tissues in groups without GM maize application. It was determined that GSH levels were significantly decreased in Group II, Group IV and Group VI $(p<0.05)$. The lowest GSH level was detected in liver tissues of second generation GM maize treated rabbits as $0.19 \mathrm{mg} \mathrm{g}^{-1}$. Insecond generation GM maize treated rabbits, kidney and liver GSH levels were 1.60 and 1.57 times lower than the parental counterpart, respectively.

Genetic modification allows the introduction of new genes, information and products into the organism. However, these new genes, which are expected to give them the desired and superior properties, can also cause unwanted metabolic changes, which can be a source of stress in living organisms. These changes may lead to the production of chemicals which may be toxic or allergic to cells. If these genetically modified products with toxic or allergic content are consumed, various disorders can occur in organisms (Çelik and Balık, 2007; Özcan, 2009).

Consumption of these products may cause alterations especially in the immune and antioxidant systems. There is 
a balance between antioxidant and oxidant system in healthy cells and degradation of this balance causes oxidative stress in the cells. Decrease in antioxidant components or increase in oxidant molecules in cells may cause an imbalance and the cell may become abnormal (Ferretti et al., 2005; Lutskii and Esaulenko, 2007). In this study, the decrease in glutathione levels in GM maize-fed rabbits confirms this phenomenon.

As the generation progressed in GM treated groups, MDA levels increased and GSH levels decreased in liver and kidney tissues. The increase in MDA levels is an indication of oxidative damage. And GSH becomes oxidized to neutralize the oxidative damage and the reduced GSH level is decreased (Zhou et al., 2001; Haschek et al., 2010). Also, the increase observed in liver tissue weights after GM maize treatment can be explained by hypertrophy of liver against oxidative damage (Thadhani et al., 1996). Liver hypertrophy can be explained by the microsomal enzyme induction in tissues exposed to oxidative damage and certain xenobiotics. The increase in liver enzymes observed in GM soya fed rabbits confirms this explanation (Tudisco et al., 2006). Different effects of GM crops on the liver have been demonstrated with similar studies. Liver atrophy in rats fed with GM potatoes, liver lesions and presence of various toxicity indicators in rats fed with $\mathrm{GM}$ maize are some of these effects (Winnicka et al., 2001; Burns, 2002).

It has also been observed that MDA levels increase in kidney tissue of GM maize treated rabbits and this increase is an indicator of oxidative damage in kidney tissue. This damage can lead to kidney failure and the progression of renal failure causes shrinkage and contraction in the kidneys. The reduction of kidney weights in GM maize treated generations can be explained by such a kidney failure (Vendomois et al., 2009).

In the literature, the effect of GM maize on oxidative parameters has not yet been sufficiently investigated, but more work on blood parameters is needed. Nevertheless, there are no studies in which the effect of GM products has been followed for three generations. In a study conducted by Vendômois et al., (2009), tissue weight changes in rats fed with genetically modified maize varieties were investigated in one generation and negative effects on the liver and kidneys were reported. Hashimoto et al. (1999) reported a statistically insignificant increase in serum $\mathrm{Na}$ and $\mathrm{Cl}$ levels in rats treated with GM potatoes. In another study conducted by Seralini et al., significant increase in creatinine levels was observed in GM maize fed to male mice (Seralini et al., 2012). These increases in biochemical parameters are explained by the disruption in the filtration process as a result of renal damage.

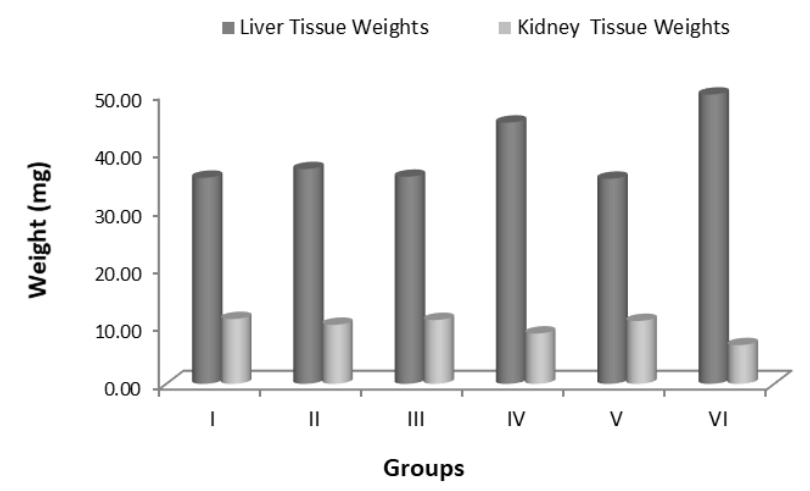

Figure 1. The effects of GM maize treatment on liver and kidney tissue weights

Table 1. The effect of GM maize treatment on MDA levels

\begin{tabular}{lccc}
\hline & Group & Liver MDA (nmole $\mathbf{~}^{-1}$ ) & Kidney MDA (nmole $^{-1}$ ) \\
\hline \multirow{2}{*}{ Parental } & I & $0.37 \pm 0.07^{c}$ & $0.48 \pm 0.07^{c}$ \\
\cline { 2 - 4 } I.Generation & II & $0.34 \pm 0.03^{c}$ & $0.49 \pm 0.06^{c}$ \\
\hline \multirow{2}{*}{ II.Generation } & III & $0.34 \pm 0.03^{c}$ & $0.48 \pm 0.06^{c}$ \\
\cline { 2 - 4 } & IV & $0.64 \pm 0.08^{\mathrm{b}}$ & $0.70 \pm 0.05^{\mathrm{b}}$ \\
\cline { 2 - 4 } & $\mathrm{V}$ & $0.33 \pm 0.03^{\mathrm{c}}$ & $0.47 \pm 0.06^{\mathrm{c}}$ \\
\hline
\end{tabular}

$\overline{a b c}$ Within a column, means not sharing the same letter are significantly different $(p<.05)$

Table 2. The effect of GM maize treatment on GSH levels

\begin{tabular}{lccc}
\hline & Group & Liver GSH $\left(\mathbf{m g ~ g}^{-1}\right)$ & Kidney GSH (mg g \\
\hline \multirow{2}{*}{ Parental } & I & $0.31 \pm 0.04^{\mathrm{ab}}$ & $0.40 \pm 0.04^{\mathrm{a}}$ \\
\hline \multirow{2}{*}{ I.Generation } & $\mathrm{II}$ & $0.30 \pm 0.06^{\mathrm{ab}}$ & $0.40 \pm 0.05^{\mathrm{a}}$ \\
\hline \multirow{2}{*}{ II.Generation } & $\mathrm{III}$ & $0.31 \pm 0.03^{\mathrm{ab}}$ & $0.39 \pm 0.05^{\mathrm{a}}$ \\
\cline { 2 - 4 } & $\mathrm{IV}$ & $0.26 \pm 0.04^{\mathrm{b}}$ & $0.32 \pm 0.03^{\mathrm{b}}$ \\
\cline { 2 - 4 } & $\mathrm{V}$ & $0.32 \pm 0.03^{\mathrm{a}}$ & $0.39 \pm 0.03^{\mathrm{a}}$ \\
\hline
\end{tabular}

${ }^{a b c}$ Within a column, means not sharing the same letter are significantly different $(p<.05)$

\section{Conclusion}

The most important focus point on genetically modified foods is that the negative effects of these foods on human health and natural environment. Findings of allergic shock fed with hazelnut genus added GM soybean, tumor development in mice fed continuously with GM foods has caused a great deal of public feedback. Although there are several studies to evaluate the potential adverse effects of genetically modified products on human health and the environment, these studies are not enough to give clear 
information yet. In this context, the results of the present study suggest that multidimensional studies on the effects of GM crops should be undertaken and scientists should be encouraged in this regard. The development and consumption of GM crops should be improved to comply with the Biosafety Law and competent persons who will apply these legislation should be trained. All food products on the market should be subject to GMO analysis and laboratory infrastructures should be strengthened, whereas labeling regulations should be applied. In this way, the production and consumption of GM crops are under control and potential toxic effects will be liminated.

\section{Acknowledgement}

This study was supported by grants from Giresun University Scientific Research Projects Department (FEN-BAP-A-250414-62).

\section{References}

Beutler E., Duron O.and Kelly B.M. (1963), Improved method for the determination of blood glutathione, J Lab Clin Med., 61, 882-888.

Brake J. and Vlachos D. (1998), Evaluation of transgenic event 176 "Bt" corn in broiler chickens, Poult Sci., 77, 648-53.

Burns J.M. (2002). 13-Week Dietary Subchronic Comparison Study with MON 863 Corn in Rats Preceded by a 1-Week Baseline Food Consumption Determination with PMI Certified Rodent Diet, Monsanto Company Report.

Çelik V. and Balık D.T. (2007). Genetically Modified Organisms (GMO), EUJST, 23(1-2),13-23.

Dickerson G.W. (2008). Specialty Corns: Guide H-232. Cooperative Extension Service, College of Agriculture and Home Economics, New Mexico State University.

El-Sanhoty R., Shahwan T. and Ramadan M.F. (2006), Application of Artificial Neural Networks to Develop a Classification Model Between. Genetically Modified Maize (Bt-176) and Conventional Maize by Applying Lipid Analysis Data, J Food Compost Anal., 19(6), 628-636.

Ferretti G., Bacchetti T., Principi F., Di Ludovico F., Viti B., Angeleri VA., Danni M. and Provinciali L. (2005), Increased levels of lipid hydroperoxides in plasma of patients with multiple sclerosis: a relationship with paraoxonase activity, Mult Scler J., 11, 677-682.

Gürer H., Özgünes R., Neal D.R., and Spitz N. (1998), Antioxidanteffects of $\mathrm{N}$-acetylcysteine and succimer in red blood cells from lead-exposed rats, Toxicology., 128, 181-189.

Halford N.G. (2012). Genetically Modified Crops 2 nd Edition. Imperial College Press, London, UK.

Haschek WM., Rousseaux CG. and Wallig MA. (2010), Fundamentals of Toxicologic Pathology, 2nd ed. Academic Press, San Diego, 197-235.

Hashimoto W., Momma K., Katsube T., Ohkawa Y., Ishige T., Kito M., Utsumi S. and Murata K. (1999), Safety assessment of genetically engineered potatoes with designed soybean glycinin: compositional analyses of the potato tubers and digestibility of the newly expressed protein in transgenic potatoes, J. Sci. Food Agric., 79, 1607-1612.

Kızıl M. and Çay M. (2010), Protective effects of Vitamin E and Selenium on blood and tissues lipid peroxidation and some antioxidant enzyme levels in rats exposed to Benzo(A)Pyrene, F.U. Health Sci. Vet. JI, 24(2), 81-85.
Lutskii MA. and Esaulenko IE. (2007). Oxidant stress in the pathogenesis of multiple sclerosis, Neurosci Behav Physiol., 37, 209-213.

Özcan S. (2009), Corn, Indispensable crop of the modern world: Contribution of genetically modified (transgenic) corn on agricultural production, TJSR, 2(2), 01-34.

Pompella A., Visvikis A., Paolicchi A., De Tata V. and Casini AF. (2003), The changing faces of glutathione, a cellular protagonist, Biochem Pharmacol., 66(8), 1499-503.

Santos M.T., Valles J., Aznar J. and Vilches J. (1980), Determination of plasma malondialdehyde-like material and its clinical application in stroke patients, J Clin Pathol., 33(10), 973-6.

Seralini G.E., Clair E., Mesnage R., Gress S., Defarge N., Malatesta M., Hennequin D., Spiroux de Vendômois J. (2012), Long term toxicity of a Roundup herbicide and a Roundup-tolerant genetically modified maize, Food Chem Toxicol., 50, 4221-4231.

Thadhani R., Pascual M. and Bonventre J.V. (1996), Acute Renal Failure, N Engl J Med., 334(22), 1448-1460.

Tudisco N., Lombardi P., Bovera F., d'Angelo D., Cutrignelli M.I., Mastellone V., Terzi V., Avallone L. and Infascelli F. (2006), Genetically Modified Soya Bean in Rabbit Feeding: Detection of DNA Fragments and Evaluation of Metabolic Effects by Enzymatic Analysis, Anim Sci., 82, 193-196.

Vendomois JSD., Roullier F., Cellier D. and Séralini G. (2009), A comparison of the effects of three GM corn varieties on mammalian health, Int J Biol Sci., 5(7),706-726.

Winnicka A., Sawosz E., Klucinski W., Kosieradzka I., Szopa J., Malepszy S. and Pastuszewska B. (2001), A note on the effect of feeding genetically modified potatoes on selected indices of non-specific resistance in rats, Journal of Anim Feed Sci., 10, 13-18.

Yoshioka T., Kawada K., Shimada T. and Mori M. (1979), Lipid peroxidation in maternal and cord blood and protective mechanism against activated oxygen toxicity in the blood, $\mathrm{Am}$. J. Obstet. Gyn., 135, 372-376.

Zhou Z.Y., Sugawara K., Mawatarı K., Matsukawa T., Líu Z. W., Devadas M., and Kato S. (2001), Reactive oxygen species uncouple external horizontal cells in the carp retina glutathione couples the magain, Neurosci., 102, 959-967. 